\title{
BMJ Open Effect of family practice contract services on the quality of primary care in Guangzhou, China: a cross-sectional study using PCAT-AE
}

\author{
Lina Li, ${ }^{1}$ Chenwen Zhong, ${ }^{1}$ Jie Mei, ${ }^{1}$ Yuan Liang, ${ }^{1}$ Li Li, ${ }^{2}$ Li Kuang ${ }^{1}$
}

To cite: Li L, Zhong C, Mei J, et al. Effect of family practice contract services on the quality of primary care in Guangzhou, China: a cross-sectional study using PCAT-AE. BMJ Open 2018;8:e21317. doi:10.1136/ bmjopen-2017-021317

- Prepublication history for this paper is available online. To view these files, please visit the journal online (http://dx.doi. org/10.1136/bmjopen-2017021317).

Received 22 December 2017 Revised 19 June 2018 Accepted 1 August 2018
A) Check for updates

(C) Author(s) (or their employer(s)) 2018. Re-use permitted under CC BY-NC. No commercial re-use. See rights and permissions. Published by BMJ.

${ }^{1}$ Institute of Social Medicine and Health Management, School of Public Health, Sun Yat-sen University, Guangzhou, China ${ }^{2}$ Department of Family Medicine and Community Health, Case Western Reserve University, Cleveland, Ohio, USA

Correspondence to Professor Li Kuang; kuangli@mail.sysu.edu.cn

\section{ABSTRACT}

Objective Current healthcare reform in China has an overall goal of strengthening primary care and establishing a family practice system based on contract services. The objective of this study was to determine whether contracting a general practitioner (GP) could improve quality of primary care.

Design A cross-sectional study using two-stage sampling conducted from June to September 2014. Propensity score matching (PSM) was employed to control for confounding between patients with and without contracted GP. Setting Three community health centres in Guangzhou, China.

Participants 698 patients aged 18-89 years.

Main outcome measures The quality of primary care was measured using a validated Chinese version of primary care assessment tool (PCAT). Eight domains are included (first contact utilisation, accessibility, continuity, comprehensiveness, coordination, family-centredness, community orientation and cultural competence from patient's perceptions).

Results A total of 692 effective samples were included for data analysis. After PSM, 94 pairs of patients were matched between the patients with and without contracted GPs. The total PCAT score, continuity (3.12 vs 2.68 , $p<0.01$ ), comprehensiveness ( 2.31 vs $2.04, p<0.01$ ) and family-centredness ( 2.11 vs $1.79, \mathrm{p}<0.01)$ were higher in patients who contracted GPs than those did not. However, the domains of first contact utilisation (2.74 vs 2.87 , $p=0.14$ ) and coordination ( 1.76 vs $1.93, p<0.05)$ were lower among patients contracted with GPs than in those who did not.

Conclusion Our findings demonstrated that patients who had a contracted GP tend to experience higher quality of primary care. Our study provided evidence for health policies aiming to promote the implementation of family practice contract services. Our results also highlight further emphases on the features of primary care, first contact services and coordination services in particular.

\section{INTRODUCTION}

Family practice is often considered the core of primary care, which is the first level of professional care that is provided to populations without restrictions on access and where the majority of the population's health needs
Strengths and limitations of this study

- This study is the first to provide evidence showing that patients with contracting general practitioners (GPs) have better experience with regard to quality of primary care in health community centres in China.

- The study adopted a validated Chinese version of Primary Care Assessment Tool Adult Edition to evaluate the quality of family practice contract services.

- To effectively adjust for confounders and facilitate comparability between the two groups, propensity score matching was used.

- A potential bias in the study is that patients who had experienced higher quality of primary care were more willing to contract with GPs.

- The data in our study were obtained only from the city of Guangzhou, which might limit the generalisability of the results to other regions.

are addressed. ${ }^{12}$ In many countries, patients usually receive primary care from general practitioners (GPs). ${ }^{3}$ Evidence has shown that reported quality of care is higher for GPs than for non-GPs, ${ }^{4}$ and that GPs can promote long-term provider-patient relationships, which ensures that the practitioners have better knowledge of their patients as people rather than symptoms, enhances communication and reduces the risk of conflicts and misunderstandings. ${ }^{5}$ A large body of research also indicates that family practices reduce hospitalisation costs, ${ }^{6}$ provide more effective and equitable care, ${ }^{7}$ and improve the quality of care that is received. ${ }^{8-10}$

However, the development of family practices in China has been limited. ${ }^{11}$ The primary care system is the bottom, secondary hospitals are the middle and tertiary hospitals are the top tier of China's three-tiered healthcare delivery system. ${ }^{12}$ Patients can access primary care in all facilities across all three levels and have the freedom to choose a doctor or healthcare facility without the constraints 
associated with a health insurance policy. ${ }^{13}$ Since market-oriented reforms were implemented in the 1980s, China's primary healthcare system has faced huge challenges, such as a shortage of qualified health personnel, insufficient government investment, weak medical technologies and rapidly increasing medical expenditures. ${ }^{14}$ Most people increasingly prefer higher level hospitals over primary care institutions because the latter are associated with poor medical technology and the perception that the providers are of lower technical quality, even though patients can see the same doctor every time they visit a primary care institution. ${ }^{15}$ These factors have led to poor accessibility and high medical costs for people seeking medical care in hospitals. ${ }^{16}$

To address these problems, China launched a new round of healthcare reform in 2009 to strengthen primary care and establish a family practice system. ${ }^{17}$ The State Council issued the Guidance on Establishing a General Practitioners System in 2011 and Guidance on the Promotion of Family Practice Contract Services in 2016, as well as plans to extend family practice contract services to the entire population by $2020 .^{18}$ The family practice contract services is aimed at fostering a closer relationship between residents and GPs, which will strengthen primary care by reorganising services to better achieve the main features of primary care. ${ }^{19}$ Patients voluntarily sign a contract with a GP whom they freely choose. After signing a contract with a patient, the physician then serves as the usual source of care (USC) and the first contact of care for the entire health system. Patients can still transfer to the hospital by themselves. The government awarded GPs $¥ 30-¥ 60$ according to the number of patients signed, the standardised management rate of chronic diseases (in particular, such as diabetes and hypertension) and the satisfaction of contracted patients. In response to this national policy, 10 model cities were initially selected to implement a pilot programme of family practice contract services in 2012, and the programme was subsequently expanded to more cities.

The city of Guangzhou was one of the first batches of pilot cities in China to implement a family practice contract service. Guangzhou is the capital of Guangdong province and has a population over 14 million people. The effort to expand health insurance coverage in Guangzhou is growing, and this has reduced the financial barriers to healthcare services. ${ }^{20}$ Medical insurance agencies encourage residents to visit community health centres (CHCs) by adopting differential payment mechanisms. The aim of implementing family practice contract services in Guangzhou is to guide residents to visit a CHC to improve the quality of care they receive.

Previous evaluations of the family practice contract services have focused on the number of contracted patients, the patient's awareness, service utilisation and patient satisfaction..$^{21}{ }^{22} \mathrm{Du}$ et al and Kuang et al compared the perceived quality of primary care between patients with and without a USC, and found that patients with a USC reported higher quality of primary care experience compared with those without a USC. ${ }^{83}$ However, we are not aware of any study conducted in China that evaluates the quality of family practice contract services. Using a primary care assessment tool (PCAT), an instrument that was designed to evaluate the attainment of the features of primary care,${ }^{24-26}$ we aim to assess the quality of family practice contract services on patient perception. To adjust for confounders and improve causal inferences, propensity score matching (PSM) was employed in our study. ${ }^{27}$

\section{METHODS}

\section{Design and participants}

This study was conducted in the city of Guangzhou, China, which implemented a family practice service programme in 2014. A two-stage sampling method was adopted. In the first stage, typical sampling was used to select three CHCs. One government-owned CHC and one private-owned $\mathrm{CHC}$ that were both granted as a statelevel demonstration CHC, and another ordinary government-owned CHC were selected. In the second stage, convenience sampling was used to select patients in each CHC to participate in the survey. Based on the standard sample size formula for a cross-sectional study, a target sample size of 280 was set for each CHC given a type I error of 0.05 , type II error of 0.1 and refusal rate of $10 \%{ }^{29}$

Data collection was performed from June 2014 to September 2014. The interviewers were four postgraduate students at Sun Yat-sen University who were trained by two researchers in advance so that they could assist the patients in completing the questionnaires. One-on-one, face-to-face interviews were conducted to guarantee the quality of the survey. Patients who participated in the survey were given a small gift as a token of appreciation on completion of the questionnaire.

Patients were interviewed in the waiting areas. The inclusion criteria were as follows: (1) patients who were 18 years old or older and could speak Mandarin or Cantonese; (2) patients who were visiting GPs and (3) those who had visited the same CHC at least three times in the last year, as they were considered to have a better understanding of the primary care services provided by GPs. ${ }^{30}$ The exclusion criteria were as follows: (1) patients who were in poor physical condition and could not complete the survey and (2) patients who could not understand the content of questionnaire.

\section{Measures}

We assessed primary care quality using the PCAT-Adult Edition, which is an instrument with good validity and reliability in China. ${ }^{30} 31$ It measures the following main domains of primary care: first contact, continuity, comprehensiveness, coordination, family-centredness, community orientation and cultural competence. These domains have been identified as the core functions of primary care. $^{32}$ The pilot test, which focused on item wording, was conducted in three CHCs in Guangzhou. ${ }^{33}$ Twenty patients were selected through convenience sampling 
to complete the questionnaire in each of the CHCs. Through the pilot test, the item wording was further revised for clarity. Modifications were made only when it was deemed that some specific items were not applicable in the Chinese context. For example, 'home safety, like getting and checking smoke detectors and storing medicines safely' was eliminated because it was considered to be inappropriate or unrealistic in the current Chinese healthcare system.

The Chinese version of the questionnaire consisted of 42 items. One item was used to identify whether the patient contacted a GP. Twenty-five items assessed the eight domains of primary care, and the remaining items were mainly used to reflect the patients' socioeconomic characteristics, health status and service utilisation. The extent to which services were received by patients was determined using a 4-point Likert scale ( $1=$ never; $2=$ sometimes; $3=$ often and 4=always). An additional option of 'Do not know/Not sure' was added in case of a lack of knowledge regarding a certain item, and this option was assigned a value of 2.5 to be consistent with the same kind of researches used PCAT in other countries. ${ }^{25} 34$

\section{Statistical analysis}

A total of 698 patients completed the questionnaires, with a response rate of $82 \%$. Six patients were excluded from the analysis because of missing relevant data. Six hundred and ninety-two effective samples were included ultimately for data analysis. The propensity score was constructed using common logistic regression model in which potential confounding variables were considered independent variables, including gender, age, household, marital status, education, occupation, medical insurance, period of time since the first visit, number of GP visits in the past year, chronic conditions and self-perceived health status, ${ }^{823}{ }^{35}$ PSM was employed through a nearest neighbour matching algorithm with a match tolerance of 0.1. After PSM, a total of 94 patients in the group with a contracted GP were matched with 94 patients in the group without a contracted a GP.

Continuous variables were reported as the mean $\pm \mathrm{SD}$, and categorical variables were reported as frequencies (\%). To compare patients who contracted for family practice services with those who did not, we used $\mathrm{X}^{2}$ analyses to compare sociodemographic characteristics and health status before and after matching. Independent samples t-tests were used to analyse the individual and total primary care attribute scores that were reported by the two groups of patients before and after matching. The level of significance was $\mathrm{p}<0.05$. All analyses were performed using SPSS V.22.

\section{Patient and public involvement}

The present study was initially promoted by patients' comments about experiences changed in quality of primary care when they contracted a GP in previous study. ${ }^{23}$ Patients were not involved in the design, recruitment or conduct of the study.
RESULTS

\section{Demographic characteristics of primary care patient visits}

Table 1 provides an overview of our study sample's demographic and socioeconomic characteristics, health status and service utilisation before and after matching. Before matching, there were significant differences in many characteristics between respondents who contracted a GP and those who did not. Compared with respondents who did not have a contracted GP, patients with a contracted GP were more likely to be older adults $(42.6 \%$ vs $55.3 \%$, $\mathrm{p}<0.05)$ and retired $(68.2 \%$ vs $79.8 \%, \mathrm{p}<0.05)$. Similarly, there was a higher proportion of patients with at least one chronic condition in the group of patients with a contracted GP than in the group without $(79.8 \%$ vs $57.4 \%$, $\mathrm{p}<0.05)$ and those with a contracted GP were more likely to have had more than six visits in the past year $(77.7 \%$ vs $60.4 \%, \mathrm{p}<0.05)$. Most patients receiving family practice contract services were local residents $(87.2 \%)$ with medical insurance $(94.7 \%)$.

After matching based on propensity scores, the above differences were eliminated, and covariate balance was achieved for these critical factors across contract status groups. Figure 1 presents the distribution of propensity scores before and after matching for our comparison: patients who did and did not contract a GP. These data indicate the extent of the differences prior to matching and the success of the PSM strategy in achieving balance in measured covariates between the groups. Prior to matching, differences were also apparent between those who did and did not contract a GP. In the groups matched for these contrasts, the differences were likewise reduced or eliminated.

\section{Primary care attribute scores}

Figure 2 shows the bivariate relationships between the patients with and without a contracted GP and the scores for primary care attributes before and after matching. Before matching, respondents who contracted a GP reported a significantly higher total PCAT score than those who did not (17.34 vs $15.08,95 \%$ CI 1.62 to 2.90 ). In the comparison of total mean scores on each of the eight primary care domains, respondents reported the highest score on continuity (2.70), followed by first-contact utilisation (2.63) and the lowest score on community orientation (1.23). After matching, total PCAT scores were significantly higher in respondents who contracted a GP than in those who did not (17.34 vs $16.36,95 \%$ CI 0.16 to 1.80 ). In the comparison of total mean scores on each of the eight primary care domains, respondents reported the highest score on continuity (2.90), followed by first-contact utilisation (2.81) and the lowest score on community orientation (1.40).

When these results were compared with those obtained before matching, we found that after matching, the reported scores were significantly higher in the domains of continuity ( 3.12 vs $2.68,95 \%$ CI 0.21 to 0.67 ), comprehensiveness (2.31 vs 2.04, 95\% CI 0.11 to 0.43 ) and family-centredness (2.11 vs $1.79,95 \%$ CI 0.10 to 0.54 ) in 
Table 1 Sample characteristics of respondents' primary care visits in the city of Guangzhou among patients with and without a contracted GP before and after PSM

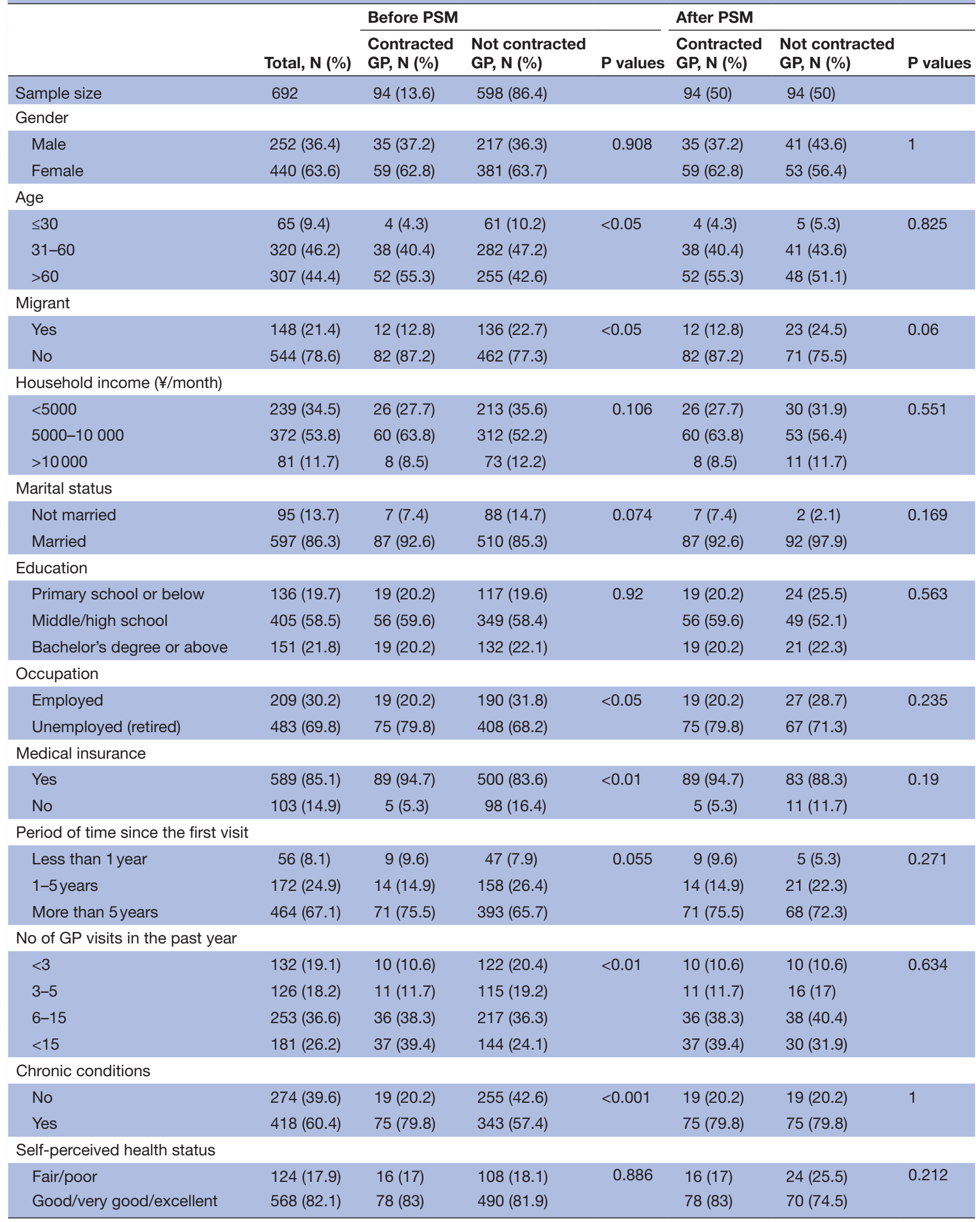

$P$ values are based on $\chi^{2}$ tests of differences between those who contracted a GP and those who did not. GP, general practitioner; PSM, propensityscore matching. 


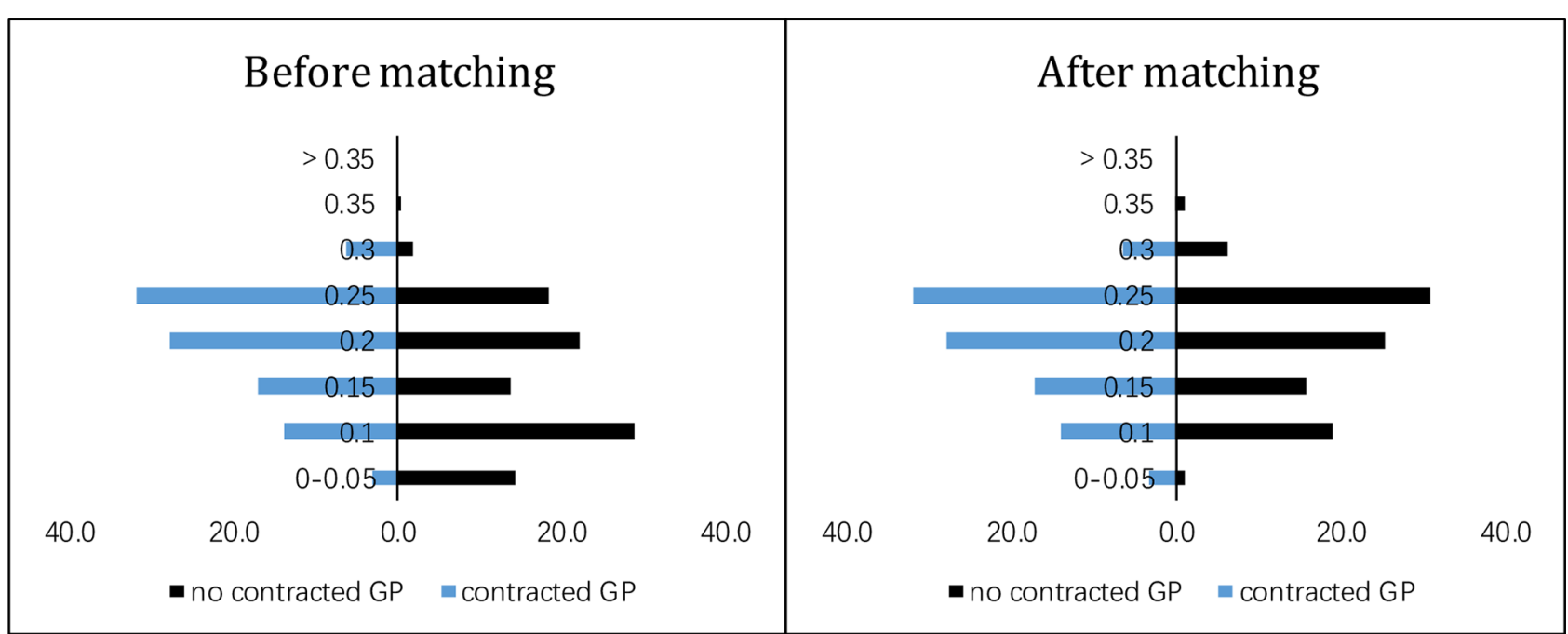

Figure 1 Distribution of propensity scores before and after matching for our comparison of patients who contracted a GP and those who did not contract a GP. GP, general practitioner.

respondents with a GP than in those without. In particular, respondents seeing a GP reported lower scores on the first-contact utilisation $(2.74$ vs $2.87,95 \% \mathrm{CI}-0.29$ to 0.03 ) and coordination ( 1.76 vs $1.93,95 \% \mathrm{CI}-0.30$ to -0.04) domains than those who did not.

The radar chart shown in figure 3 provides more detail about the quality of primary care between patients who did and did not contract a GP before and after PSM. In figure $3 \mathrm{~A}$, it is apparent that respondents who contracted a GP had higher scores overall than those who did not contract one. Figure 3A also provides detailed information on each subdomain. Patients who contracted a GP had higher scores on each subdomain, especially continuity, comprehensiveness, family-centredness, community orientation and cultural competence. Moreover, figure $3 \mathrm{~A}$ shows that the gap in scores between those who did and did not contract a GP was largest in the comprehensiveness subdomain, in which the scores are 2.31 and

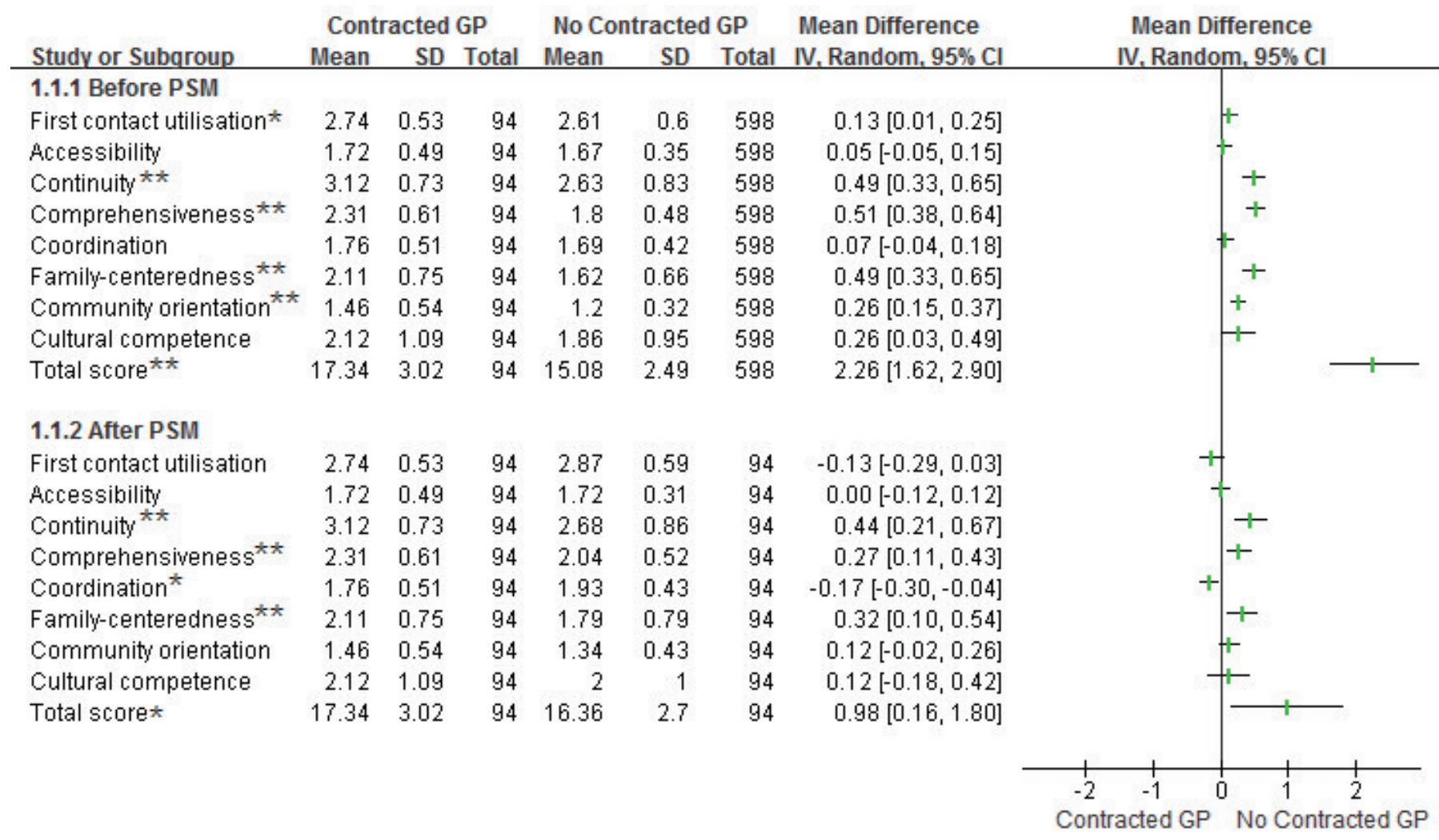

Figure 2 Associations between family practice contract services and primary care attributes before and after $P S M$. ${ }^{*} P<0.05$, ${ }^{\star \star} \mathrm{P}<0.01$, based on independent samples t-test of difference between those contracted GP and those did not. GP, general practitioner; IV, inverse variance; PSM, propensity score matching. 


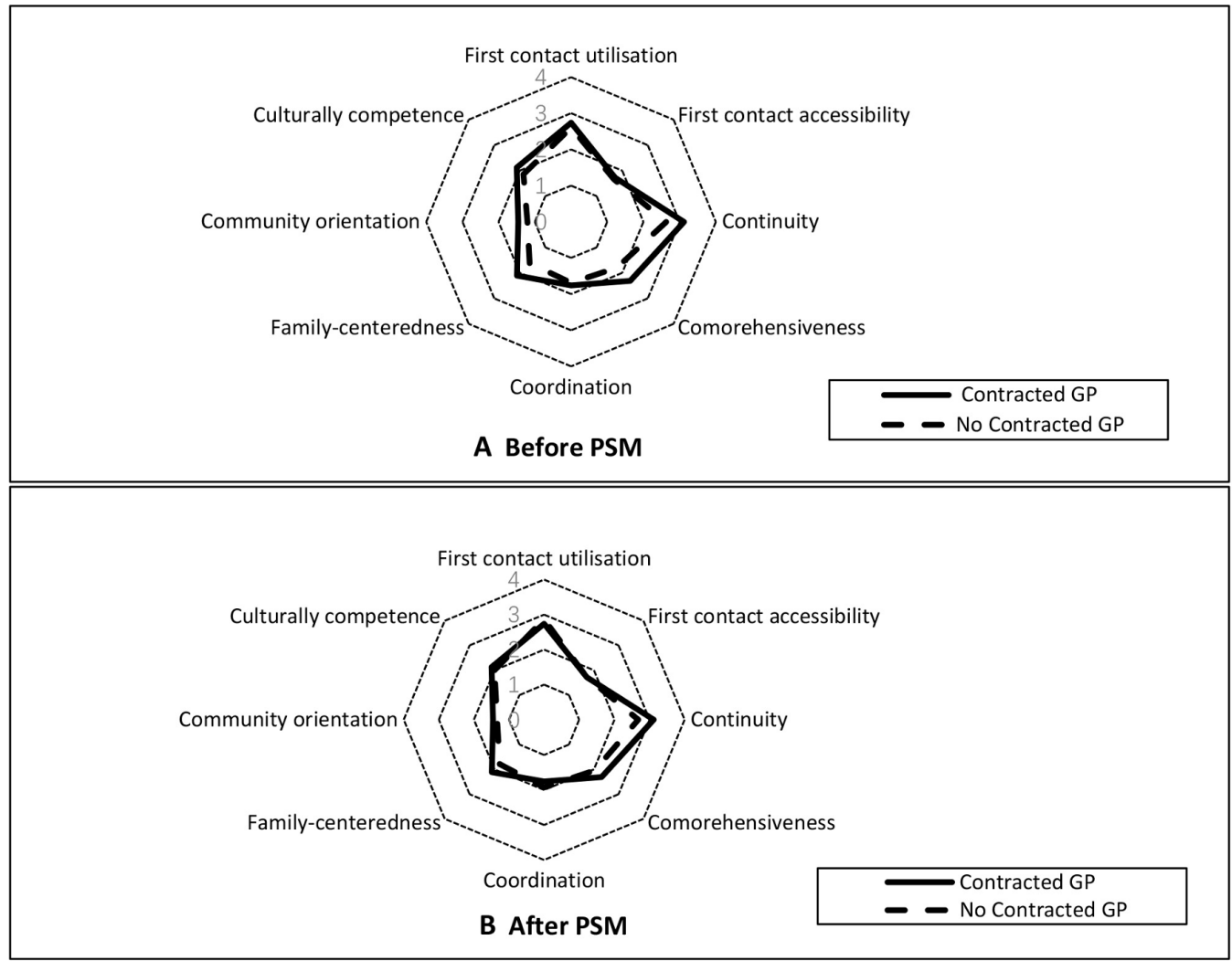

Figure 3 Family practice contract services and primary care attributes before and after PSM. GP, general practitioner; PSM, propensity score matching.

1.8, respectively. Figure 3B reveals that the data showed a similar pattern after matching, with some differences. The PCAT scores between the two groups became closer for each domain, and the contracting group had a lower score in the domain of first contact utilisation and coordination. Moreover, the largest difference between the groups was in the continuity domain.

\section{DISCUSSION}

In this cross-sectional study, we used an internationally and locally validated tool, the PCAT, to analyse information collected from patient surveys in Guangzhou, China with the aim of exploring the effects of family practice contract services on the quality of primary care that patients perceived they received. We found that total PCAT scores were significantly higher in patients who contracted a GP than in those who did not. Previous studies used PCAT to assess the quality of primary care between different types of healthcare providers or healthcare settings, ${ }^{35-38}$ and the results of those studies showed that the use of a GP was associated with a higher quality of primary care. A study performed in Hong Kong showed that reported primary care experiences were better in patients who primarily received their care from GPs than in those who did not. ${ }^{39} 40$ Therefore, in part, these findings imply that primary care is strengthened when services are reorganised to better achieve the main features of primary care.
The respondents who contracted a GP reported higher overall PCAT scores as a result of their higher scores on continuity, comprehensiveness and family-centredness, but they reported lower PCAT score on the coordination domain after matching. There are several possible explanations for this finding. The higher score for continuity could be explained by the fact that patients who contracted a GP could see the same doctor when they suffered health problems and that they therefore developed a continuing relationship with their physician. The better performance in the family-centredness domain may suggest that GPs take care of their patients and care for their patients' families. The findings were consistent with the results of a study by Tsai $e t$ al, who found that patients with a USC reported higher quality experiences for ongoing care and family-centredness than were reported by patients without a USC. ${ }^{36}$ Patients who contracted a GP were much more likely than those who did not to have a USC.

Previous studies have shown that the benefits of comprehensive care can be inferred from the known benefits of preventive care and from the benefits of providing services known to be effective for populations with particular health need. ${ }^{31}$ GPs who contract with patients are required to provide a range of primary care services, including providing periodic health assessments, home care services and traditional Chinese medicine as well as promoting the early detection of and follow-up 
consultations for chronic conditions, ${ }^{18}$ which might be some reasons for the higher comprehensiveness score of patients with a contracted GP.

There were no differences between the two groups' PCAT scores on the domains of first contact utilisation, accessibility, community orientation and cultural competence. The likely reason for these results is that CHCs were established as the preferred primary care providers in Guangzhou, and which makes it easier to access a healthcare provider. ${ }^{35}$ Every resident can reach a CHC on foot within $15 \mathrm{~min}$, and the medical equipment in these facilities is gradually being improved. Basic public health services are fully implemented in CHCs, and programmes that allow transfer training and continuing education by community GPs are also being strengthened. ${ }^{11}$ Hence, even patients who do not contract a GP can still access healthcare.

On the other hand, the scores on the coordination domain (1.76 vs $1.93, \mathrm{p}<0.05)$ were lower among patients who contracted a GP than in those who did not. We then compared the items under coordination of care and found that the medical record item 'Did your GP write down any information for the specialist about the reason for the visit?' (2.55 vs $3.05, \mathrm{p}<0.01)$ reported a significantly lower score among patients who contracted a GP than those who did not. The lower score could be explained by the fact that there was no specific medical record (referral letter) for the physicians to use to refer the patients to another care service provider in China primary care practice. ${ }^{42}$ Instead, referrals were mostly done by oral notification of referral information, or by directly informing the accepting provider about patient's condition by phone by the referring GP. Previous studies conducted in the USA have shown that GPs provide and coordinate care for a wide variety of patient problems ${ }^{43}{ }^{44}$ and that they prioritise these competing demands on the basis of relationships that are developed during multiple patient visits over time. There is no perfect and fluent referral system in China, and family practice in China is still in its infancy. Making major changes to an entire system and medical practice is always difficult. It is especially difficult to improve family practice in China because medical education traditionally did not include family medicine, and the population is accustomed to seeking primary care in tertiary settings, such as hospitals. Moreover, the challenges represented by the disparity in community involvement between rural and urban settings are also major bottlenecks that hinder the development of the family practice system in China. ${ }^{45}$

There are several limitations to this study. First, due to the pilot nature of the family practice contract programme, the data in our study were obtained only from the city of Guangzhou, which might limit the generalisability of the results to other regions. Second, although PSM theoretically balances covariates between groups, such balance is difficult to prove, especially with regard to unmeasured variables. Third, a potential bias in the study is that patients who had experienced higher quality of primary care were more willing to contract with GPs, which may bias results. Despite these limitations, the findings from this study are helpful in informing policy decisions and practice. The government should continue putting efforts into implement the family practice contract services and strengthen primary care, especially in the context of an ageing population and increasing prevalence of chronic diseases.

\section{CONCLUSION}

Our findings demonstrated that patients who had a contracted GP tend to experience higher quality of primary care, which provided evidence for policies to promote the implementation of family practice contract services. Further efforts should place emphases on the strength of the features of primary care, especially first contact and coordination services.

Acknowledgements The authors would like to thank all of the healthcare staff in the community health centres in Guangzhou, China for their enormous on-site support during the data collection process.

Contributors $\mathrm{LnL}$ is the first author. LK obtained funding. LK and $\mathrm{LnL}$ conceived the study. LK provided overall guidance, including advice related to the study design and instrument development. YL and JM collected the data. LnL, CZ, YL and JM were involved in data cleaning. LNL, LK and CZ conducted the data analysis. LnL, $\mathrm{LK}$ and $\mathrm{CZ}$ contributed to the literature search and the interpretation of the data. LnL wrote the first draft. LK and LL contributed feedback on study results and approved the final version of the manuscript that was submitted for publication. All authors read and approved the final manuscript.

Funding This work was supported by the National Natural Science Foundation of China (grant no: 71673311).

Competing interests None declared.

Patient consent Obtained.

Ethics approval The Institutional Review Board of Sun Yat-sen University reviewed and approved the protocol of the study in compliance with the Declaration of Helsinki.

Provenance and peer review Not commissioned; externally peer reviewed.

Data sharing statement № additional data are available.

Open access This is an open access article distributed in accordance with the Creative Commons Attribution Non Commercial (CC BY-NC 4.0) license, which permits others to distribute, remix, adapt, build upon this work non-commercially, and license their derivative works on different terms, provided the original work is properly cited, appropriate credit is given, any changes made indicated, and the use is non-commercial. See: http://creativecommons.org/licenses/by-nc/4.0/.

\section{REFERENCES}

1. Kringos DS, Boerma WG, Hutchinson A, et al. The breadth of primary care: a systematic literature review of its core dimensions. BMC Health Serv Res 2010;10:65.

2. Starfield B. Is primary care essential? The Lancet 1994;344:1129-33.

3. Starfield B. Primary care: balancing health needs, services and technology. New York: Oxford University Press, 1998.

4. Zou Y, Zhang X, Hao Y, et al. General practitioners versus other physicians in the quality of primary care: a cross-sectional study in Guangdong Province, China. BMC Fam Pract 2015;16:134.

5. Safran DG, Karp M, Coltin K, et al. Measuring patients' experiences with individual primary care physicians. Results of a statewide demonstration project. J Gen Intern Med 2006;21:13-21.

6. Chetty VK, Culpepper L, Phillips RL, et al. FPs lower hospital readmission rates and costs. Am Fam Physician 2011;83:1054.

7. Starfield B, Shi L. The medical home, access to care, and insurance: a review of evidence. Pediatrics 2004;113(5 Suppl):1493-8. 
8. Du Z, Liao Y, Chen CC, et al. Usual source of care and the quality of primary care: a survey of patients in Guangdong province, China. Int $J$ Equity Health 2015;14:60.

9. Weiss LJ, Blustein J. Faithful patients: the effect of long-term physician-patient relationships on the costs and use of health care by older Americans. Am J Public Health 1996;86:1742-7.

10. Honeyford K, Baker R, Bankart MJ, et al. Modelling factors in primary care quality improvement: a cross-sectional study of premature $\mathrm{CHD}$ mortality. BMJ Open 2013;3:e003391.

11. Li X, Lu J, Hu S, et al. The primary health-care system in China. The Lancet 2017;390:2584-94.

12. Wei $\mathrm{X}$, Zou G, Zhang $\mathrm{H}$, et al. Implementation of the Chinese national microscopy centre policy: health facility survey in Shandong Province. Trop Med Int Health 2011;16:847-53.

13. Ji L, Newman J, Lu J, et al. Understanding the standard of care in the treatment of type 2 diabetes in China: results from a national survey. Chin Med J 2014;127:3524-9.

14. Wang $\mathrm{Y}$, Wilkinson $\mathrm{M}, \mathrm{Ng} \mathrm{E}$, et al. Primary care reform in China. $\mathrm{Br} \mathrm{J}$ Gen Pract 2012;62:546-7.

15. Wu D, Lam TP, Lam KF, et al. Health reforms in china: the public's choices for first-contact care in urban areas. Fam Pract 2017;34:cmw133-200.

16. Goetz K, Hess S, Jossen M, et al. Does a quality management system improve quality in primary care practices in Switzerland? A longitudinal study. BMJ Open 2015;5:e007443.

17. Chen Z. Launch of the health-care reform plan in China. Lancet 2009;373:1322-4.

18. National Health Commission of the People's Republic of China, 2016. Guidance on the promotion of family practice contract service. http://www.nhfpc.gov.cn/tigs s3577/201606/e3e7d2670a8b4163b1fe 8e409c7887af.shtml

19. Starfield B, Shi L, Macinko J. Contribution of primary care to health systems and health. Milbank Q 2005;83:457-502.

20. Chen W, Zhang Q, Renzaho AMN, et al. Social health insurance coverage and financial protection among rural-to-urban internal migrants in China: evidence from a nationally representative crosssectional study. BMJ Glob Health 2017;2:e000477.

21. Wei $L$. The performance evaluation based on the demand side of the family doctor contract service: A focus on chronic diseases. Chinese Journal of Health Policy 2016;8:23-30.

22. Bao-hua Q. A comparative study on the health services utilization and satisfaction of the family doctor service. Chinese Journal of Health Policy 2016;08:31-6.

23. Kuang L, Liang $Y$, Mei J, et al. Family practice and the quality of primary care: a study of Chinese patients in Guangdong Province. Fam Pract 2015;32:557-63.

24. Shi L, Starfeld B, Politzer R, et al. Validating the adult primary care assessment tool. Fam Pract 2001;50:161.

25. Lee JH, Choi YJ, Sung NJ, et al. Development of the Korean primary care assessment tool-measuring user experience: tests of data quality and measurement performance. Int J Qual Health Care 2009;21:103-11.

26. Macinko J, Almeida C, de Sá PK. A rapid assessment methodology for the evaluation of primary care organization and performance in Brazil. Health Policy Plan 2007;22:167-77.
27. Baek S, Park SH, Won E, et al. Propensity score matching: a conceptual review for radiology researchers. Korean $J$ Radiol 2015;16:286-96.

28. D'Agostino RB. Propensity score methods for bias reduction in the comparison of a treatment to a non-randomized control group. Stat Med 1998;17:2265-81.

29. Shi L, Starfield B, Xu J, et al. Primary care quality: community health center and health maintenance organization. South Med J 2003;96:787-95.

30. Yang H, Shi L, Lebrun LA, et al. Development of the Chinese primary care assessment tool: data quality and measurement properties. Int $J$ Qual Health Care 2013;25:92-105.

31. Wang W, Shi L, Yin A, et al. Development and validation of the Tibetan primary care assessment tool. Biomed Res Int 2014;2014:1-7.

32. Institute of Medicine. Defining Primary Care: An Interim Report. Washington (DC: National Academies Press (US), 1994.

33. Mei J, Liang Y, Shi L, et al. The development and validation of a rapid assessment tool of primary care in China. Biomed Res Int 2016;2016:1-13.

34. Rocha KB, Rodríguez-Sanz M, Pasarín Ml, et al. Assessment of primary care in health surveys: a population perspective. Eur $J$ Public Health 2012;22:14-19.

35. Wang HH, Wong SY, Wong MC, et al. Patients' experiences in different models of community health centers in southern China. Ann Fam Med 2013;11:517-26.

36. Tsai J, Shi L, Yu WL, et al. Usual source of care and the quality of medical care experiences: a cross-sectional survey of patients from a Taiwanese community. Med Care 2010;48:628-34.

37. Hu R, Liao Y, Du Z, et al. Types of health care facilities and the quality of primary care: a study of characteristics and experiences of Chinese patients in Guangdong Province, China. BMC Health Serv Res 2016;16:335.

38. Feng S, Shi L, Zeng J, et al. Comparison of primary care experiences in village clinics with different ownership models in Guangdong Province, China. PLoS One 2017;12:e0169241.

39. Lam CL, Leung GM, Mercer SW, et al. Utilisation patterns of primary health care services in Hong Kong: does having a family doctor make any difference? Hong Kong Med J 2011;17(suppl 3):28-32.

40. Mercer SW, Siu JY, Hillier SM, et al. A qualitative study of the views of patients with long-term conditions on family doctors in Hong Kong. BMC Fam Pract 2010;11:46.

41. Haggerty JL, Beaulieu MD, Pineault R, et al. Comprehensiveness of care from the patient perspective: comparison of primary healthcare evaluation instruments. Healthc Policy 2011;7:154-66.

42. Yu M J, Li L, Kuang L. Framework of the referral system in primary care practice[J]. Chinese General Practice 2018;21:375-81.

43. Stange KC, Jaén CR, Flocke SA, et al. The value of a family physician. Fam Pract 1998;46:363-8.

44. Baicker K, Chandra A. Medicare spending, the physician workforce, and beneficiaries' quality of care. Health Aff 2004;4:184-97.

45. Wang HH, Wang JJ, Zhou ZH, et al. General practice education and training in southern China: recent development and ongoing challenges under the health care reform. Malays Fam Physician 2013:8:2-10. 